\title{
Alcohol exposure during pregnancy altered childhood developmental trajectories in a rural South African community
}

Davies, Leigh-Anne; Cockcroft, Kate; Olinger, Lynda; Chersich, Matthew; Urban, Michael; Makkan, Candice M. Chetty; Turnbull, Oliver H.; Olivier, Leana; Viljoen, Denis

\section{Acta Paediatrica}

DOI:

10.1111/apa.13978

Published: 01/11/2017

Peer reviewed version

Cyswllt i'r cyhoeddiad / Link to publication

Dyfyniad o'r fersiwn a gyhoeddwyd / Citation for published version (APA):

Davies, L-A., Cockcroft, K., Olinger, L., Chersich, M., Urban, M., Makkan, C. M. C., Turnbull, O. H., Olivier, L., \& Viljoen, D. (2017). Alcohol exposure during pregnancy altered childhood developmental trajectories in a rural South African community. Acta Paediatrica, 106(11), 18021810. https://doi.org/10.1111/apa.13978

\footnotetext{
Hawliau Cyffredinol / General rights

Copyright and moral rights for the publications made accessible in the public portal are retained by the authors and/or other copyright owners and it is a condition of accessing publications that users recognise and abide by the legal requirements associated with these rights.

- Users may download and print one copy of any publication from the public portal for the purpose of private study or research.

- You may not further distribute the material or use it for any profit-making activity or commercial gain

- You may freely distribute the URL identifying the publication in the public portal ?
}

Take down policy

If you believe that this document breaches copyright please contact us providing details, and we will remove access to the work immediately and investigate your claim. 
Alcohol exposure during pregnancy altered childhood developmental trajectories in a rural South African community

Authors: Leigh-Anne Davies ${ }^{1 *}(\mathrm{PhD})$; Kate Cockcroft $^{1}(\mathrm{PhD})$; Lynda Olinger $^{2}(\mathrm{MSc})$; Matthew Chersich $^{3}$, (PhD); Michael Urban ${ }^{4}(\mathrm{MD})$; Candice M Chetty Makkan ${ }^{5}(\mathrm{PhD})$; Oliver H Turnbull ${ }^{1}$ $(\mathrm{PhD})$; Leana Olivier ${ }^{4,6}$ (BA Hons); Denis Viljoen ${ }^{4,6}(\mathrm{PhD})$

${ }^{1}$ Department of Psychology, School of Human and Community Development, University of Witwatersrand, Johannesburg, South Africa

${ }^{2}$ School of Health Systems \& Public Health, Faculty of Health Sciences, University of Pretoria

3 Wits Reproductive Health and HIV Institute, Faculty of Health Sciences, University of Witwatersrand, South Africa

${ }^{4}$ Division of Molecular Biology and Human Genetics, University of Stellenbosch, Western Cape, South Africa

${ }^{5}$ The Aurum Institute, Johannesburg, South Africa

${ }^{6}$ Foundation for Alcohol Related Research (FARR), Cape Town, South Africa

\section{Correspondence:}

Leigh-Anne Davies

Department of Psychology, School of Human and Community Development

University of Witwatersrand, Johannesburg, South Africa

leighanne.davies@gmail.com 


\begin{abstract}
Aim: This study examined the effects of prenatal alcohol exposure on childhood development trajectories in a rural South African community between 2003 and 2008.
\end{abstract}

Methods: We assessed 121 children at 7-12 months (year one) and 5-6 years (year five) using the Griffiths Mental Developmental Scales - Extended Revised, which measures sensorimotor, cognitive and social development, with lower scores indicating developmental delay. We also interviewed their mothers or caregivers. Three groups were identified: 29 with fetal alcohol syndrome (FAS) or partial FAS (pFAS), 57 more who had been exposed to alcohol and 35 controls who had not.

Results: The scale's total score was higher in the controls than in the FAS/pFAS group at years one and year five and in the alcohol exposed group at year five. Many groups' trajectories declined when compared with global norms, but the trajectories in the FAS/pFAS and the alcohol exposed groups declined more than the controls for eye-hand and performance and total score. Earlier pregnancy recognition in the FAS/pFAS group correlated strongly $(r=-0.77)$ with higher GQ in year five.

Conclusion: FAS/pFAS and prenatal alcohol exposure affected the Griffiths scores more than the control group. Efforts are needed to detect pregnancy early and reduce alcohol exposure.

Keywords: developmental trajectories; early childhood development; foetal alcohol syndrome; prenatal alcohol exposure; South Africa 


\section{KEY NOTES}

- We examined the effects of prenatal alcohol exposure on childhood development trajectories in a rural South African community between 2003 and 2008 using the Griffiths Mental Developmental Scales - Extended Revised.

- Our prospective study of 121 children showed heavy maternal alcohol consumption affected overall development at 7-12 months, with lower levels of alcohol affecting higher order abilities at 5-6 years.

- Efforts are needed to detect pregnancy early and reduce alcohol exposure. 


\section{INTRODUCTION}

Prenatal alcohol exposure can cause devastating structural and functional abnormalities in the developing fetus, which manifests as cognitive and developmental deficits in children. Heavy prenatal alcohol exposure, especially binge drinking $(1,2)$, is classically associated with fetal alcohol spectrum disorder (FASD), which encompasses a continuum of physical, cognitive and behavioural outcomes (2-4). These outcomes include lowered intellectual ability $(1,4,5)$ and deficits in language $(4,6)$, motor skills $(7,8)$ attention $(9)$ and behaviour $(10)$.

Functional deficits in areas of higher order cognition, such as executive functions, are commonly described in children prenatally exposed to alcohol and these include planning, organising, sequencing, problem solving $(11,12)$ and working memory $(8,13)$. These cognitive deficits reflect the fundamentals of learning and may even occur in the absence of facial features associated with fetal alcohol syndrome (FAS) or partial fetal alcohol syndrome (pFAS). In this situation the link between cause and effect makes it difficult to identify non-syndromic alcohol exposed children $(2,4)$. While the amount and timing of alcohol intake is an important determinant of FASD outcomes, there is evidence that individual susceptibility and other risk factors play a big role.

Within the context of early childhood development, it is clear that a complex interplay of factors, in addition to alcohol exposure, are critical determinants of child outcome. Importantly, negative consequences of the cumulative effects of socio-economic deprivation on development may accrue over time (14). Other factors include prenatal and postnatal nutrition, birth weight, maternal age, maternal body mass index, parity, maternal stress and depression, a family history of neurodevelopmental disorders, parenting styles, neglect and general lack of stimulation (1517). 
While considerable research exists describing the developmental deficits of children exposed to heavy prenatal alcohol use, as described above, there is surprisingly little data available on early developmental profiles and trajectories of children with varying degrees of prenatal alcohol exposure in low-income and middle-income countries. The study provided a unique opportunity to assess early developmental domains in a poorly-resourced population that we knew had a high prevalence of FASD. This study aimed to compare the developmental trajectories of children with FAS/pFAS, children who were exposed to alcohol during pregnancy but did not meet the criteria for FAS/pFAS and controls whose mothers did not drink during pregnancy. Our special focus was on the alcohol exposed group. The study also assesses the role of other factors associated with poor developmental outcome.

\section{METHODS}

Participants were recruited, between 2003 and 2008, from a sheep farming area in the Upper Karoo region of the Northern Cape, once the largest railway junction in South Africa. When railway operations were significantly reduced due to route restructuring, the high unemployment and concomitant socio-economic deprivation that occurred as a result contributed to the already high levels of alcohol abuse in the area. This area of South Africa is well known to researchers in the field of FASD, as it has one of the highest reported incidences of FASD in the world and this has been described in a school-entry population (3).

Data for this study were drawn from a larger FASD prevention study in the Northern Cape (18). This analysis, followed the study children up to five years of age, extending previous data when the children were between 7-12 months of age and 17-21 months of age $(18,19)$. Written informed consent was obtained from the mothers' at all three points. The mothers of 500 children born in the local hospital between 2002 and 2003 were invited to participate. Of those children 
born, 394 were assessed at 7-12 months of age, year one and 135 returned when they were between five to six years of age, year five (Figure 1). Differences in the sample size between years one and five were mostly due to resource constraints, which precluded the selection of more control participants, and this meant that 247 were not invited back at year five. The loss of seven participants because of death or mobility issues and 19 with missing data further reduced the sample size (Figure 1). At years one and five, the participants were evaluated at a local community centre, by two paediatricians with training in medical genetics, for dysmorphic features and neurological signs associated with FAS or pFAS (2).

A semi-structured questionnaire, piloted within the local population, was administered to biological mothers at year one, by a trained interviewer or neuropsychometrist (20). Some mothers were interviewed at a later assessment between 17-21 months of age. Where the mothers died or were untraceable, shorter proxy interviews were conducted with the primary caregiver. The tool elicited maternal demographic and lifestyle information, such as the occurrence and amount of maternal drinking and smoking. A history of maternal alcohol consumption in pregnancy was obtained through a maternal interview using a timeline follow-back method (2). Referrals were made to specialist services where necessary and feedback on the child's development was provided to families. The study was approved by the University of the Witwatersrand Ethics Committee for Research on Human Subjects (numbers M01/11/20; M09/02/22).

Inclusion in this analysis depended on the child having completed both clinical and neurodevelopmental assessments at year one and five and the mother having completed a maternal interview. A final diagnosis of FAS and pFAS was made at the year five assessment, based on the revised Institute of Medicine criteria (2). In brief, a diagnosis of FAS required the 
presence of at least two of three characteristic facial features, namely short palpebral fissures $\left(<10^{\text {th }}\right.$ percentile), thin vermilion border and, or, smooth philtrum of the lip, as well as growth deficiency - based on $\leq 10^{\text {th }}$ percentile for height and weight, or head circumference - and evidence of central nervous system abnormalities. A pFAS diagnosis required at least two of three facial features listed above as well as either: growth deficiency, evidence of central nervous system abnormalities and, or, unexplained cognitive/behavioural abnormalities. Although the clinical diagnoses of both FAS and pFAS are considered distinctive in the absence of confirmed maternal alcohol consumption during pregnancy (2), our criteria required a history of alcohol use in pregnancy.

The alcohol exposed group comprised children who were non-symptomatic for FAS/pFAS features, but whose mothers confirmed drinking prior to the recognition of their pregnancy or at any point during their pregnancy. The controls consisted of participants with no evidence of clinical FAS/pFAS features and no reported alcohol exposure during pregnancy. Children were assigned to one of the three groups (Figure 1): 29 (24\%) in the FAS/pFAS group, 57 (47\%) in the alcohol exposed group and 35 (29\%) in the controls group. Of the 29 children diagnosed with FAS/pFAS at year five, four (14\%) had been classified as alcohol exposed at year one and just one changed from a FAS/pFAS diagnosis at year one to a non-exposed case at year five.

\section{$<<$ Insert Figure 1 >>}

\section{Neurodevelopmental study measures}

The Griffiths Mental Developmental Scales - Extended Revised (GMDS-ER) assesses three key developmental domains over six scales from infancy to middle childhood, namely: sensorimotor development, which focuses on gross and fine motor coordination, as measured by the locomotor 
and eye-hand scales; cognitive development associated with higher order abilities such as manipulation, problem solving and reasoning, measured by the language, performance and practical reasoning scales and social development, measured by the personal-social scale (21). The general quotient (GQ), which determines overall development, is a composite of these six subscale scores. Means range between 99.87 and 100.46, with standard deviation scores from 0.58 to 17.43 (21). A standard score of 100 would place the child's performance within the average range whereas a score below 70 ( $<2$ standard deviations) would indicate a significant degree of developmental delay (22). Age equivalents or mental age, based on tables from the analyses manual, were used in conjunction with the chronological age and plotted as developmental trajectories for the total GQ and each subscale. The only exception was the practical reasoning scale, as this was only measured at year five. Age-appropriate versions of the GMDS-ER measured developmental functioning at years one and five, with prematurity corrected at year one. The GMDS-ER was developed in the United Kingdom and although it does not provide normal measures for South African children, it has been extensively used to assess the development of local children in the country $(22,23)$. Existing Afrikaans and Xhosa translations were used. The developmental outcomes of the GMDS-ER subscales were not used for the diagnosis of FAS/pFAS. Although a new third edition of the tool has since been developed, previous versions of the tool assess similar constructs of childhood development.

\section{Statistical analyses}

Analyses were carried out using Intercooled Stata 12.1 (Stata Corporation, Texas, USA). Continuous data across the three groups were analysed using the Kruskal-Wallis analysis of variance for non-normal variables and one way ANOVA for normally-distributed variables. Where significant differences were observed across the groups, further post-hoc analyses were 
carried out using Mann-Whitney U and Student's t-tests, to compare differences between the controls and alcohol exposed groups and between controls and FAS/pFAS groups. Frequency distributions and chi-square tests were used for analysing the categorical data. Pearson's correlation coefficients identified univariate linear associations between the normally-distributed variables, birth weight and the GMDS-ER subscale scores, as well as the associations between the year one and year five GMDS-ER subscale scores for the three groups. A series of Spearman's correlation coefficients $(r)$ were used to detect univariate associations between all other non-normal variables and the GMDS-ER subscale scores, for outcomes at both year one and year five for each group. Finally, multiple linear regressions were used to identify factors associated with total GQ scores at years one and five. The model selection was based on backward elimination of non-significant factors $(p>0.05)$, the clinical significance of factors based on existing evidence and the relative quality of the model as measured by the Akaike Information Criterion. Alcohol use during pregnancy was excluded from the multivariate regression model, as it is a proximal variable on the causal chain between FAS/pFAS and neurological outcomes.

\section{RESULTS}

The sample characteristics, by study group are shown in Table 1. As expected, infants diagnosed with FAS/pFAS were smaller in terms of length and head circumference at birth and much more likely to be premature: $31 \%$ versus $3 \%$ of controls and $12 \%$ of alcohol exposed subjects. They were also much more likely to be underweight at birth, defined as $\leq 2.5 \mathrm{~kg}$ : $64 \%$, versus $18 \%$ of controls and $24 \%$ of alcohol exposed subjects. Significant anthropometric differences continued between the groups at years one and five $(p<0.001)$. For many of the indices measured, including alcohol units per week during pregnancy, the levels in the alcohol exposed group were midway 
between those of the FAS/pFAS subjects and the controls. For example, 54\% of the mothers of alcohol exposed children smoked during pregnancy (30/56), about equidistant from the levels in the controls $(17 \%, 6 / 35)$ and FAS/pFAS women $(76 \%, 22 / 29)$.

\section{$<<$ Insert Table 1>>}

\section{Group differences}

In terms of overall development, the total GQ means shown in Table 2 indicated no significant differences between the control and alcohol exposed groups at year one, but notable differences by year five $(p=0.026)$. The subscales which contributed to the decline at year five included poor eye-hand coordination, performance and practical reasoning. The mean scores were numerically lower than the controls for the FAS/pFAS group over all domains at both time points, when compared to the alcohol exposed and control groups.

\section{$<<$ Insert Table 2>>}

\section{Effects of prenatal alcohol exposure on developmental trajectories}

Within the FAS/pFAS group, language, eye-hand coordination and performance deteriorated the most over time and at approximately the same rate (Figure 2). While locomotor abilities improved by year five, personal-social skills remained fairly constant. Similar patterns of development were observed in the alcohol exposed group, with notable declines observed in both the performance and language subscales. A large disparity was noted between the scores at year five in locomotor and personal-social, which both improved steadily, when compared to the remaining subscales, which all deteriorated. Steady trajectory declines were also evident over time in the control group with regard to language, eye-hand coordination and performance skills. 


\section{$<<$ Insert Figure 2>>}

To account for anticipated delay among the FAS/pFAS group, mental age equivalent scores were plotted for all groups over the total GQ. The GQ trajectories increased steadily over time, with the control and alcohol exposed groups following a similar pattern of development. The FAS/pFAS group showed a trajectory than ran below and parallel to both the control and alcohol exposed groups. This parallel trajectory suggests that, while development was delayed in onset, it generally occurred at the same rate in the three groups. When chronological and mental age performances were compared, slower developmental rates become evident for all groups.

\section{Effects of socio-demographic variables on development}

Correlations were sought between the GMDS-ER sub-scale and GQ scores and the following variables: maternal educational level, marital status, occupation, parity, gestational month of pregnancy recognition, duration of breast feeding, reported level of pre-pregnancy alcohol consumption, infant gender, ethnicity, presence of prematurity, birth weight, length and head circumference. The only strong correlation that was detected was between gestational month of pregnancy recognition and neurodevelopmental outcome at year five in the FAS/pFAS group. This was true for GQ ( $\mathrm{r}=-0.77)$, and was consistent across all domains, except for practical reasoning. A similar correlation was not found for the alcohol exposed group.

Several other statistically significant, but weaker, correlations were also found for GQ as significance levels did not reach $\leq 0.5$ for any other variable). In the control group, higher GQ at year five correlated with mothers being married, rather than cohabiting or single $(\mathrm{r}=-0.48)$, and with being Black African compared with mixed ethnicity $(\mathrm{r}=0.36)$. For the alcohol exposed group, higher GQ at year one, but not year five, correlated negatively with maternal parity $(\mathrm{r}=$ - 
0.42) and age $(\mathrm{r}=-0.34)$. In the FAS/pFAS group a similar correlation was found for parity $(\mathrm{r}=$ 0.37), but not age $(r=-0.04)$. Lastly, and only in the alcohol exposed group, the year one GQ correlated with infant head circumference $(\mathrm{r}=0.27)$, and the year five GQ correlated with the reported level of alcohol consumption $(\mathrm{r}=-0.32)$. Maternal educational level had no detectable effect.

Multiple regression analysis examined factors associated with total GQ scores at year one and year five, in multivariate models that included the study group. The above analyses identify associations separately for each study group. Due to missing data, the gestational month at pregnancy recognition variable could not be included in this analysis. In the multivariate model for year one, there were significant associations with birth length at 0.73 , with a $95 \%$ confidence interval $(95 \% \mathrm{CI})$ of 0.24 to $1.22(p=0.001)$ and maternal parity $(-3.04,95 \% \mathrm{CI}-4.59$ to -1.50 , $p<0.001)$. At year five, the association with birth length remained similar $(0.80,95 \% \mathrm{CI} 0.28$ to 1.33; $p=0.003)$ and there was an association with maternal age $(0.53,95 \%$ CI 0.12 to 0.93 , $p=0.01)$. There was also an association with two of the study groups: alcohol exposed $-5.71,95 \%$ CI -11.28 to $-0.14(p=0.05)$ FAS/pFAS $-12.06,95 \%$ CI -20.04 to $-4.07(p=0.003)$.

\section{DISCUSSION}

This prospective study compared the developmental trajectories from year one to year five for

prenatally alcohol-exposed children without syndromic features to those of children with FAS/pFAS and to unexposed controls, in a poorly-resourced rural community in South Africa. The differences between the groups at year five, when the children were 5-6 years, were considerably larger than those reported in the same cohort when children were younger at 7-12 months and 17-21 months of age (19). As expected, infants diagnosed with FAS/pFAS performed worse at both year one and year five over most developmental domains when 
compared to other groups and struggled most with the higher-order cognitive tasks associated with manipulation and regulation. This difficulty with higher-cognitive functions, which becomes even more apparent with age, has been well described with FAS $(7,8,11,13,19)$.

The alcohol exposed group fell between the control group and the FAS/pFAS groups in terms of alcohol consumption, but also in many other maternal and infant parameters. From a cognitive viewpoint, their GMDS-ER scores were similar at year one to the control group. However, by year five, they scored lower than the control group on the eye-hand coordination, performance and practical reasoning subscales and for the GQ as a whole. The lower GQ score at year five remained significant on multivariate analysis. The intermediate developmental status of the alcohol exposed group, as well as the correlation of year five GQ with the level of alcohol intake in this group alone, was probably consistent with a dose-related effect of ethanol exposure on brain structure and function (24). This less severe exposure would have caused subtler or more region-specific effects, with the related adverse neurodevelopmental outcomes only becoming apparent later in childhood. Equally, it was consistent with the notion that as cognitive demands increase, those with even moderate levels of prenatal alcohol exposure find these demands more challenging $(7,9,25)$.

Most children in the sample, regardless of their study group, experienced some delay in important areas of development. In all groups, the total GQ, as well as the subscales for language, eye-hand coordination and performance, declined between years one and five. This suggests that factors other than prenatal alcohol exposure affected child development in this setting. Many of the children in this study, including the controls, were exposed to other adverse life circumstances. For example, most of the mothers in all groups were unemployed and had not completed secondary education, many had experienced the death of a child and a relatively high 
proportion of infants in all groups had a low birth weight (18). It is known that neurodevelopment throughout childhood is strongly associated with socio-economic status, with children from low socio-economic status far more likely to falter compared to their wealthier counterparts (26). May et al. (24) showed that even in a South African setting with high exposure to prenatal alcohol, exposure to other poverty-related factors appeared to outweigh the effect of prenatal alcohol exposure (26). These other important factors include both biological variables, such as nutrition and growth stunting, and psychological variables such as limited child stimulation, exposure to violence and maternal depression (26). To complicate the matter, where socio-economic status is kept optimal, adoption studies have showed serious damage of the exposed children in later childhood (27).

The greater drop-off in GQ, eye-hand coordination and performance for both alcohol exposed groups compared to the control group may, therefore, either represent the effect of ethanol exposure and of other prenatal and postnatal factors, or very likely a combination of all these. Overall, our findings confirmed the importance of addressing both maternal alcohol use and the immediate environment of at-risk women and children. Examples of interventions include FASD prevention strategies, optimising antenatal care, improving child nutrition, preschool services in poorly resourced communities, parent training to provide more stimulated home environments and early developmental interventions.

It should be noted that the median maternal pre-pregnancy alcohol use was very high in the FAS/pFAS group and was relatively high even in the alcohol exposed group. Late pregnancy recognition in the FAS/pFAS group was strongly correlated with lower GQ and poorer developmental functioning over higher cognitive domains at year five. The most likely explanation is that late recognition prolonged the period of fetal exposure to alcohol. 
At year one, infants with reduced lengths at birth and higher maternal parity presented with delayed developmental trajectories. Previous studies reported how early stunting, at least partly attributable to prenatal nutritional deficiency, was associated with less schooling, poor test performances and low earnings in adulthood (14-17,28).

While we did not detect an association between ethnicity and alcohol exposure, we found a difference in neurodevelopmental outcomes between the control children of Black African and mixed ancestry. The reason for this is uncertain, but may have indicated differences in unreported drinking or in other environmental or parenting-related factors. It warrants further investigation.

\section{Study limitations}

Due to the limited size and the high-risk nature of the sample, caution should be used in extending these findings to other populations. Further limitations stem from use of the GMDSER tool, which tends to measure general ability, but is less able to detect subtle or specific delays, especially during infancy (7). Furthermore, although this tool has been extensively used in research studies, direct comparisons between different versions of the GMDS developmental ranges are prone to misinterpretation due to differing means and standard deviations of the instrument (29). The use of mental age equivalents aimed to mitigate these limitations. It should be noted that the neurodevelopmental evaluation of alcohol effects in this study was limited to typically developing abilities at five years of age. It is possible that later effects on development should be investigated at an older age using other psychometric instruments and evaluations of behaviour. 
Maternal alcohol histories are known to be sensitive and therefore potentially susceptible to bias, although there is considerable evidence that retrospective self-reports are more valid, or at least detect more alcohol use, than reports given during pregnancy (30).

\section{CONCLUSION}

All levels of prenatal alcohol exposure in this study influenced higher order cognitive abilities in children at five years of age. While participants diagnosed with FAS/pFAS were often developmentally different to the controls at year one, larger differences became evident with age. In contrast alcohol exposed children that did not meet the FAS/pFAS criteria were developmentally similar to the controls at year one, but by year five they demonstrated significantly lower functioning in the eye-hand, performance and practical reasoning domains. In addition, their GQ was considerably lower at year five, including in the multivariate analysis. The developmental trajectories of all children in the study is a matter for concern and suggests that pre-school services and other measures to stimulate child development may have a particularly critical role in this and similar local environments.

In the FAS/pFAS group, strong correlations emerged between earlier maternal pregnancy recognition and higher overall functioning in the year five GQ scores and this finding was most likely to have been mediated by reduced drinking during pregnancy. However, it does emphasise the need for effective methods of preconception screening for alcohol use among South African women, together with alcohol education and counselling for women of childbearing age and early pregnancy recognition.

\section{Acknowledgements}

The authors wish to thank the families for their participation in the study as well as clinicians, genetic counsellors and psychometrists for their time and involvement. Further thanks go to the 
staff at the Foundation for Alcohol Related Research / Joan Wertheim Centre for their recruitment, organisation and continued support to the community.

\section{Conflicts of interest}

The authors declare that they have conflicts of interests.

\section{Funding}

This study was supported by grants from the Centers for Disease Control and The Transnet Foundation. Additional administrative funds were provided by The Association for Responsible Alcohol Use and a local benefactor. None of the funders had any involvement in the study or this paper.

\section{List of Abbreviations}

FASD, Fetal Alcohol Spectrum Disorders; FAS, Fetal Alcohol Syndrome; GMDS-ER, Griffiths Mental Developmental Scales - Extended Revised; GQ, General Quotient; pFAS, Partial Fetal Alcohol Syndrome 


\section{REFERENCES}

1. Bailey BN, Delaney-Black V, Covington CY, Ager J, Janisse J, Hannigan JH et al. Prenatal exposure to binge drinking and cognitive and behavioral outcomes at age 7 years. Am J Obstet Gynecol 2004; 191: 1037-43.

2. Hoyme HE, May PA, Kalberg WO, Kodituwakku P, Gossage JP, Truijillo PM et al. A practical clinical approach to diagnosis of fetal alcohol spectrum disorders: clarification of the 1996 institute of medicine criteria. Pediatrics 2005; 115:39-47

3. Urban M, Chersich MF, Fourie LA, Chetty C, Olivier L, Viljoen D. Fetal alcohol syndrome among grade 1 schoolchildren in Northern Cape Province: prevalence and risk factors. S Afr Med J 2008; 98:877-82.

4. Mattson SN, Crocker N, Nguyen TT. Fetal alcohol spectrum disorders: neuropsychological and behavioral features. Neuropsychol Rev 2011; 21:81-101.

5. Streissguth AP, Bookstein FL, Barr HM, Sampson PD, O'Malley K, Young JK. Risk factors for adverse life outcomes in fetal alcohol syndrome and fetal alcohol effects. J Dev Behav Pediatr 2004; 25:228-38.

6. McGee CL, Bjorkquist OA, Riley EP, Mattson SN. Impaired language performance in young children with heavy prenatal alcohol exposure. Neurotoxicol Teratol 2009; 31:71-5.

7. Adnams CM, Kodituwakku PW, Hay A, Molteno CD, Viljoen D, May PA. Patterns of cognitive-motor development in children with fetal alcohol syndrome from a community in South Africa. Alcohol Clin Exp Res 2001; 25:557-62. 
8. Kalberg WO, May PA, Blankenship J, Buckley D, Gossage JP, Adnams CM. A Practical Testing Battery to Measure Neurobehavioral Ability among Children with FASD. Int J Alcohol Drug Res 2013; 26:51-60.

9. Coles CD, Kable JA, Keen CL, Jones KL, Wertelecki W, Granovska IV et al. Dose and Timing of Prenatal Alcohol Exposure and Maternal Nutritional Supplements: Developmental Effects on 6-Month-Old Infants. Matern Child Health J 2015; 19:2605-14.

10. Nash K, Rovet J, Greenbaum R, Fantus E, Nulman I, Koren G. Identifying the behavioural phenotype in Fetal Alcohol Spectrum Disorder: sensitivity, specificity and screening potential. Arch Womens Ment Health 2006; 9:181-6.

11. Mattson SN, Goodman AM, Caine C, Delis DC, Riley EP. Executive functioning in children with heavy prenatal alcohol exposure. Alcohol Clin Exp Res 1999; 23 Suppl 11:1808-15.

12. Skogerbo A, Kesmodel US, Wimberley T, Stovring H, Bertrand J, Landro NI et al. The effects of low to moderate alcohol consumption and binge drinking in early pregnancy on executive function in 5-year-old children. BJOG 2012; 119:1201-10.

13. Mattson SN, Roesch SC, Fagerlund A, Autti-Rämö I, Jones KL, May PA et al. Toward a neurobehavioral profile of fetal alcohol spectrum disorders. Alcohol Clin Exp Res 2010; $34: 1640-50$.

14. Engle PL, Black MM, Behrman JR, Cabral de Mello M, Gertler PJ, Kapiriri L et al. Strategies to avoid the loss of developmental potential in more than 200 million children in the developing world. Lancet 2007; 369:229-42. 
15. Baker-Henningham H, Powell C, Walker S, Grantham-McGregor S. Mothers of undernourished Jamaican children have poorer psychosocial functioning and this is associated with stimulation provided in the home. Eur J Clin Nutr 2003; 57:786-92.

16. Bradley RH, Corwyn RF. Socioeconomic status and child development. Annu Rev Psychol 2002; 53:371-99.

17. Carter RC, Jacobson JL, Molteno CD, Dodge NC, Meintjies EM, Jacobson SW. Fetal alcohol growth restriction and cognitive impairment. To be published in Pediatrics. [Preprint] 2016. Available from http: https://www.ncbi.nlm.nih.gov/pubmed/?term=27401098

18. Chersich MF, Urban M, Olivier L, Davies LA, Chetty C, Viljoen D. Universal prevention is associated with lower prevalence of fetal alcohol spectrum disorders in Northern Cape, South Africa: a multicentre before-after study. Alcohol Alcohol 2012; 47:67-74.

19. Davies L, Dunn M, Chersich M, Urban M, Chetty C, Olivier L et al. Developmental delay of infants and young children with and without fetal alcohol spectrum disorder in the Northern Cape Province, South Africa. Afr J Psychiatry 2011; 14:298-305.

20. Viljoen D, Croxford J, Gossage JP, Kodituwakku PW, May PA. Characteristics of mothers of children with fetal alcohol syndrome in the Western Cape Province of South Africa: a case control study. J Stud Alcohol 2002; 63:6-17.

21. Griffiths R. The Abilities of Babies. London: The Test Agency; 1986.

22. Luiz DM, Foxcroft CD, Tukulu AN. The Denver II Scales and the Griffiths Scales of Mental Development: a correlational study. Journal of child and adolescent mental health 2004; $16: 77-81$. 
23. Cockcroft K, Amod Z, Soellaart B. Level of maternal education and performance of Black, South African infants on the 1996 Griffiths Mental Development Scales. Afr J Psychiatry 2008; 11: 44-50.

24. May PA, Tabachnick BG, Gossage JP, Kalberg WO, Marais AS, Robinson LK et al. Maternal factors predicting cognitive and behavioural characteristics of children with fetal alcohol spectrum disorders. J Dev Behav Pediatr 2013; 34:314-25.

25. Kodituwakku PW, Kodituwakku EL. From research to practice: an integrative framework for the development of interventions for children with fetal alcohol spectrum disorders. Neuropsychol Rev 2011; 21:204-23.

26. Grantham-McGregor S. Early child development in developing countries. Lancet 2007 10; 369:824.

27. Streissguth AP, Barr HM, Kogan J, Bookstein FL. Understanding the occurrence of secondary disabilities in clients with fetal alcohol syndrome (FAS) and fetal alcohol effect (FAE). University of Washington Fetal Alcohol and Drug Unit Final report. Centre for Disease control and Prevention; 1996.

28. Graham K, West P, Wells S. Evaluating theories of alcohol-related aggression using observations of young adults in bars. Addiction 2000; 95:847-63.

29. Ivens J, Martin N. A common metric for the Griffiths Scales. Arch Dis Child 2002; 87:10910.

30. Poikolainen K, Leppänen K, Vuori E. Alcohol sales and fatal alcohol poisonings: a timeseries analysis. Addiction 2002; 97:1037-40. 


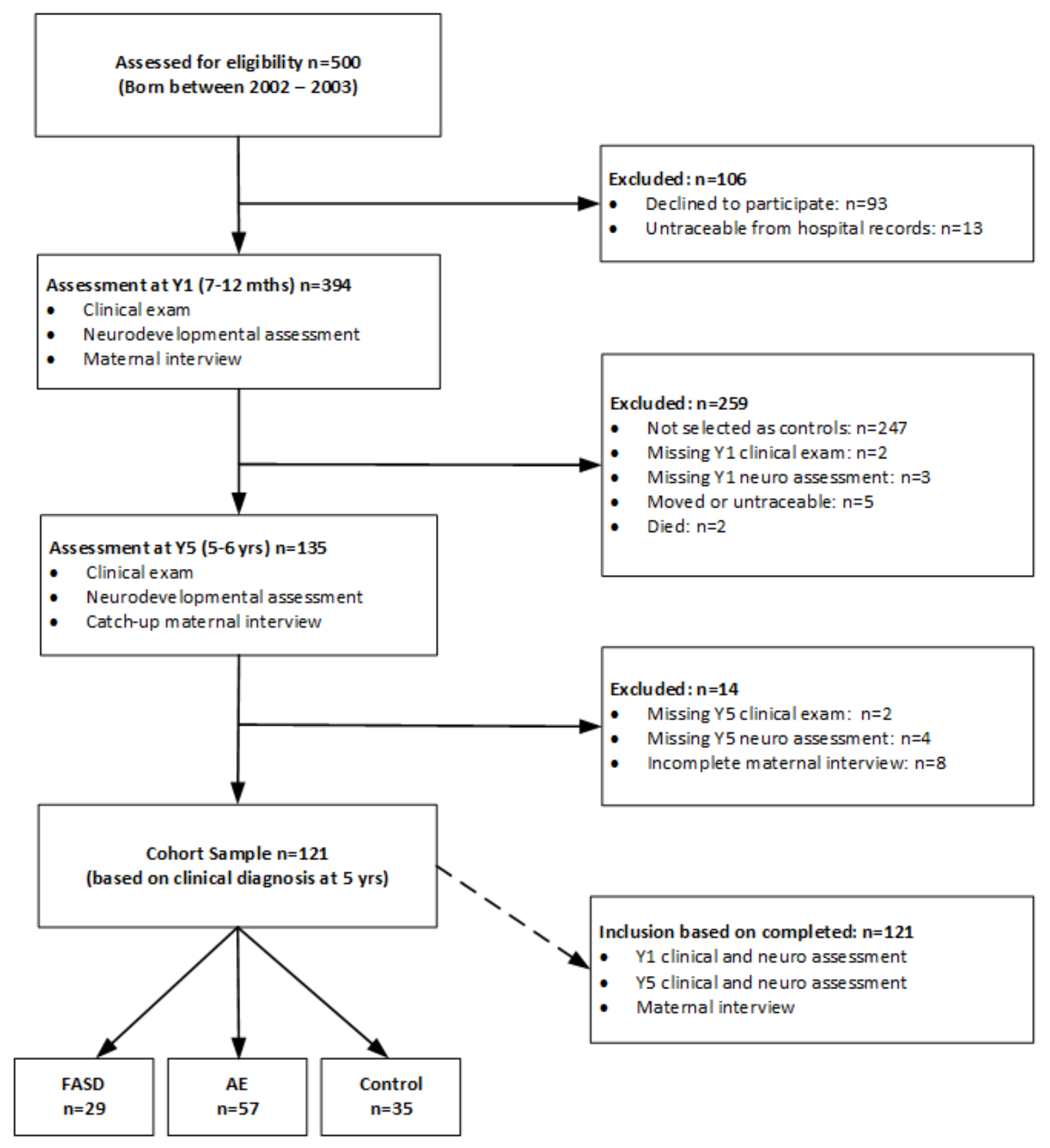

Figure 1 Recruitment and attrition of participants in study 


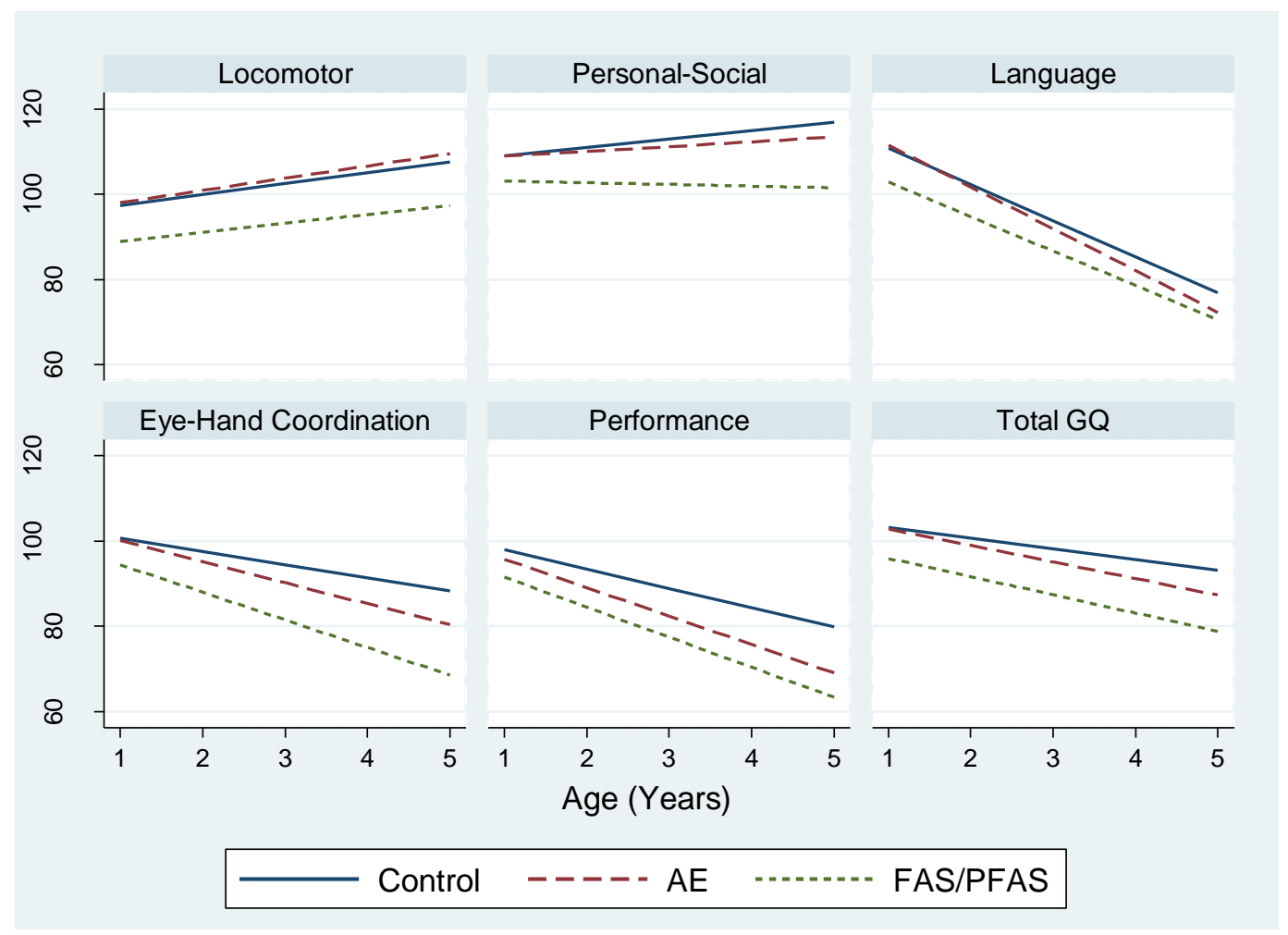

Figure 2 Trajectories of developmental abilities, comparing children with FAS/pFAS, alcohol exposure and a control group. 
Table 1 Infant, maternal, pregnancy and lifestyle variables based on FASD group allocation $(\mathrm{N}=121)$

\begin{tabular}{|c|c|c|c|c|c|c|}
\hline & Variable group & Category, n/N (\%) & $\begin{array}{l}\text { Control } \\
(35 / 121)\end{array}$ & $\begin{array}{l}\text { Alc Exposed } \\
(57 / 121)\end{array}$ & $\begin{array}{l}\text { FAS/PFAS } \\
(29 / 121)\end{array}$ & $p$ \\
\hline \multirow{7}{*}{ Infant } & Gender & Female & $22 / 35(63)$ & $31 / 57(54)$ & $18 / 29(62)$ & .663 \\
\hline & Ethnicity & Black & $7 / 35(20)$ & $10 / 57(18)$ & $7 / 29(24)$ & \\
\hline & & Mixed Ethnicity & $28 / 35(80)$ & $47 / 57(82)$ & $22 / 29(76)$ & .769 \\
\hline & Anthropometry ${ }^{+}$ & Prematurity & $1 / 35(3)$ & $7 / 57(12)$ & $9 / 29(31)$ & .005 \\
\hline & & Less than $2.5 \mathrm{~kg}$ & $6 / 33(18)$ & $13 / 55(24)$ & $16 / 25(64)$ & $<.001$ \\
\hline & & Birth length mean $\mathrm{cm}(\mathrm{sd}), \mathrm{n}$ & $49.8(3.6), 31$ & $49.2(4.1), 54$ & $45.7(5.7), 23$ & .002 \\
\hline & & Birth weight mean $\mathrm{kg}(\mathrm{sd}), \mathrm{n}$ & $2.97(0.4), 34$ & $2.77(0.6), 54$ & $2.26(0.5), 25$ & $<.001$ \\
\hline \multirow{3}{*}{ Year 1} & & Birth OFC mean cm (sd), $\mathrm{n}$ & $34.8(1.9), 32$ & $33.9(2.4), 54$ & $32.2(2.7), 25$ & $<.001$ \\
\hline & & Length mean $\mathrm{cm}(\mathrm{sd}), \mathrm{n}$ & $70.1(3.0), 35$ & $68.7(4.1), 57$ & $64.3(3.7), 29$ & $<.001$ \\
\hline & & Weight mean $\mathrm{kg}(\mathrm{sd}), \mathrm{n}$ & $8.4(1.1), 35$ & $7.6(1.5), 57$ & $5.9(0.9), 29$ & \\
\hline \multirow{3}{*}{ Year 5} & & OFC mean $\mathrm{cm}(\mathrm{sd}), \mathrm{n}$ & $45.2(1.4), 35$ & $44.5(1.8), 57$ & $42.5(1.3), 29$ & \\
\hline & & Length mean $\mathrm{cm}(\mathrm{sd}), \mathrm{n}$ & $105.6(4.4), 35$ & $101.4(6.4), 57$ & $95.3(5.7), 29$ & $<.001$ \\
\hline & & Weight mean $\mathrm{kg}(\mathrm{sd}), \mathrm{n}$ & $17.0(2.1), 35$ & $15.8(2.4), 57$ & $12.8(1.6), 29$ & \\
\hline \multirow{14}{*}{ Maternal } & & OFC mean $\mathrm{cm}(\mathrm{sd}), \mathrm{n}$ & $50.9(1.4), 35$ & $50.1(1.6), 57$ & $48.1(1.4), 29$ & \\
\hline & Maternal age $^{\dagger}$ & Mean yrs (sd), n & $25.6(6.5), 33$ & $26.8(6.2), 56$ & $31.1(6.6), 28$ & .002 \\
\hline & Marital status $^{\dagger}$ & Married/Engaged & $8 / 31(26)$ & $15 / 55(27)$ & $5 / 29(17)$ & \\
\hline & & Divorced/Widowed & $1 / 31(3)$ & $3 / 55(6)$ & $0 / 29(0)$ & \\
\hline & & $\begin{array}{l}\text { Unmarried, living with } \\
\text { partner }\end{array}$ & $5 / 31(16)$ & $14 / 55(26)$ & $16 / 29(55)$ & \\
\hline & & Single & $17 / 31(55)$ & $23 / 55(42)$ & $8 / 29(28)$ & .040 \\
\hline & Education level $^{+}$ & No formal schooling & $1 / 32(3)$ & $2 / 54(4)$ & $6 / 28(21)$ & \\
\hline & & Incomplete Primary & $2 / 31(6)$ & $9 / 54(17)$ & $9 / 28(32)$ & \\
\hline & & Complete Primary & $3 / 31(10)$ & $10 / 54(18)$ & $4 / 28(14)$ & \\
\hline & & Incomplete Secondary & $11 / 31(36)$ & $25 / 54(46)$ & $9 / 28(32)$ & \\
\hline & & Complete Secondary & $14 / 31(45)$ & $8 / 54(15)$ & $0 / 28(0)$ & $<.001$ \\
\hline & Maternal occupation ${ }^{+}$ & Full time & $10 / 31(32)$ & $10 / 54(19)$ & $1 / 29(3)$ & \\
\hline & & Part time & $5 / 31(16)$ & $11 / 54(20)$ & $5 / 29(17)$ & \\
\hline & & Unemployed & $16 / 31(52)$ & $33 / 54(61)$ & $23 / 29$ (79) & .055 \\
\hline \multirow{5}{*}{$\begin{array}{l}\text { Pregnancy } \\
\text { \& Lifestyle }\end{array}$} & Parity $^{+}$ & Mean \# of children (sd), $n$ & $2.1(1.3), 34$ & $2.7(1.6), 57$ & $3.2(1.5), 29$ & .007 \\
\hline & & Death of a child & $4 / 34(12)$ & $9 / 57(16)$ & $11 / 29(38)$ & .019 \\
\hline & $\begin{array}{l}\text { Month pregnancy } \\
\text { discovered }^{+}\end{array}$ & Mean (sd), n & $3.0(1.5), 24$ & $3.8(1.4), 34$ & $4.2(1.9), 9$ & .070 \\
\hline & $\begin{array}{l}\text { Smoking during } \\
\text { pregnancy }^{+}\end{array}$ & $\mathrm{n} / \mathrm{N}(\%)$ & $6 / 35$ (17) & $30 / 56(54)$ & $22 / 29(76)$ & $<.001$ \\
\hline & $\begin{array}{l}\text { Alcohol units/week } \\
\text { before pregnancy }^{+}\end{array}$ & median (IQR), n & $0(0), 35$ & $13(6-21), 48$ & 31 (18-61), 24 & $<.001$ \\
\hline
\end{tabular}

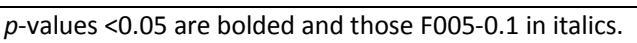

$F A S D=F e t a l$ Alcohol Spectrum Disorder; $A E=A l c o h o l$ Exposure; FAS=Fetal Alcohol Syndrome; PFAS=Partial Fetal Alcohol Syndrome; IQR=inter-quartile range; OFC=Occipital Head Circumference.

tSome data are missing 
Table 2 Differences in mean GMDS subscales at Year 1 and Year 5 between study groups

\begin{tabular}{|c|c|c|c|c|c|c|}
\hline & & Control $(A)$ & Alc expo (B) & FAS/pFAS (C) & & \\
\hline & & $(n=35)$ & $(n=57)$ & $(n=29)$ & & \\
\hline GMDS subscales & Assessment & Mean & Mean & Mean & $\begin{array}{c}\text { (A vs. B) } \\
P\end{array}$ & $\begin{array}{c}\text { (A vs. } C \text { ) } \\
P\end{array}$ \\
\hline \multirow[t]{2}{*}{ Locomotor } & Year 1 & 97.3 & 98.0 & 88.9 & .833 & .034 \\
\hline & Year 5 & 107.6 & 109.5 & 97.4 & .623 & .035 \\
\hline \multirow[t]{2}{*}{ Personal-Social } & Year 1 & 109.0 & 108.9 & 103.1 & .974 & .198 \\
\hline & Year 5 & 116.8 & 113.4 & 101.5 & .357 & .001 \\
\hline \multirow[t]{2}{*}{ Language } & Year 1 & 110.7 & 111.5 & 102.8 & .744 & .015 \\
\hline & Year 5 & 76.9 & 72.3 & 70.5 & .159 & .133 \\
\hline \multirow[t]{2}{*}{ Eye-Hand Coordination } & Year 1 & 100.6 & 100.1 & 94.4 & .870 & .135 \\
\hline & Year 5 & 88.3 & 80.3 & 68.5 & .033 & $<.001$ \\
\hline \multirow[t]{2}{*}{ Performance } & Year 1 & 97.9 & 95.7 & 91.5 & .527 & .085 \\
\hline & Year 5 & 79.9 & 69.0 & 63.3 & .002 & .001 \\
\hline Practical Reasoning $^{\Delta}$ & Year 5 & 90.1 & 81 & 73.2 & .010 & $<.001$ \\
\hline Total General Quotient & Year 1 & 103.2 & 102.8 & 95.9 & .891 & .028 \\
\hline (GQ) & Year 5 & 93.2 & 87.3 & 78.8 & .026 & $<.001$ \\
\hline
\end{tabular}

Year 1=7-12months; Year 5=5-6 years; GMDS=Griffiths Mental Developmental Scales; Alc Expo= Alcohol Exposure; FAS=Fetal Alcohol Syndrome; PFAS=Partial Fetal Alcohol Syndrome.

هPractical Reasoning subscale only included Year 5 assessment 